\title{
Correspondence Teaching Reform of Environmental Science
}

\author{
Fangyi Deng ${ }^{1, a}$, Yijian Chen ${ }^{2, b}$, Haiyun Chen ${ }^{3, c}$
}

${ }^{1,2,3}$, Key Laboratory of Ethnic Medicine Resource Chemistry, State Ethnic Affairs Commission \& Ministry of Education, School of Chemistry and Biotechnology, Yunnan University of Nationalities.Engineering Research Center of Biopolymer Functional Materials of Yunnan, Yunnan University of Nationalities. Kunming Yunnan 650500 China

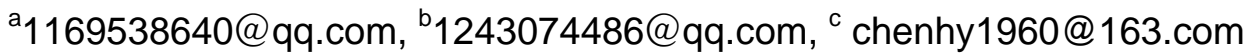

Keywords: Environmental Science, Correspondence education, Reform of teaching, Self-link

Abstract. In this paper, Environmental Sciences, the reform of teaching methods, correspondence, through the status and characteristics of environmental science education by correspondence analysis. With the author several years to engage in adult correspondence education in reality. Of environmental science and education by correspondence teaching mode, teaching methods, teaching contents, teaching methods, teaching methods, the reform put forward some ideas and proposals.

\section{Introduction $^{1}$}

Environmental Science correspondence students there is age gap, knowledge level uneven, different occupation, learning motivation of different characteristics and rules, therefore, teaching is difficult. We cannot copy the teaching mode in teaching full-time[1], should have a suitable teaching methods in correspondence education. Course of environmental science related, content, and piecemeal, hard hard to remember, experiments, and concrete, not empty, if often method, in accordance with the requirements of the syllabus content, tend to echo what the books say, make content boring, teaching effect is poor, can not adapt to the characteristics and requirements of correspondence teaching. Therefore, the need for traditional teaching mode reform. The problem of the reform of scientific teaching methods, through the analysis of the environmental science correspondence education present situation and characteristics. The author is engaged in the adult correspondence education in recent years, put forward some ideas and suggestions on the reform of environmental science education by correspondence teaching mode, teaching form, teaching content, teaching means, teaching method, attempts to provide a little help for correspondence environmental science teaching, for outstanding students of environmental science professional correspondence provides a guidance.

\section{The change of teaching mode, select the appropriate form of teaching, pay attention to the correct guidance, grasp self-study.}

Correspondence education is the "self-study, face-to-face while" teaching mode. The main way to acquire knowledge of students is self-taught, learning guidance is an important link in the correspondence teaching, we should do a good job. The class teaching hours in total have 2/3 time self-study and correspondence students counseling time, but most bear family, work, learn the three heavy pressure, although it has a strong desire for knowledge and learning ability, but often can not guarantee the time and attention, so that to guarantee the teaching quality, we must change the

1. Fund project:. Yunnan University of Nationalities teaching reform research projects (0205--02010008) This work was supported by Program for Innovative Research Team (in Science and Technology) in University of Yunnan Province (2011UY09), and Yunnan Provincial Innovation Team(2011HC008) "Experimental biotechnology of Yunnan province undergraduate teaching demonstration center" project. (0205-20010005209).

2. Corresponding Author: Fangyi Deng (1970-) , Female, master,Associate Professor, The main research directions: pharmaceutical biotechnology. 
teaching model. Select the appropriate teaching forms, such as the first to self-study, pay attention to correctly guide the students around the teaching content and the teaching syllabus, scientific arrangements for the time, formulate feasible study plan, then in accordance with the requirements of each course scientifically arranged self-study time, let the students according to the teaching content of each course, each chapter then a number of self discretion, planned, step by step self-study, self-study learning clear goals, decide on the main direction, from the shallower to the deeper, step by step. At the same time, in order to avoid self form, make effective use of the conversion, and can fully understand the students master the knowledge and learning, the teacher should write a series of operations of each course and textbook chapters, according to the order, questions should be diversified, as far as possible with multiple choice questions, supplemented by traditional [2], and distinguish with key requirements syllabus content mastery and generally understand the content, make the students know the score. Teachers should be in correspondence students with together in the first semester of the academic year of every year issued the course work to be face to face, after recovery. And undergraduate course exam marking, score together, wherein, a certain percentage of homework score for a total score, volume scores accounted for a certain percentage. So the job as part of performance, related to the vital interests of students, attention will lead to students, they will think through relapsing based on careful study, work independently, and not do things carelessly, can guarantee the quality of work. At the same time, a certain amount of homework, the students not only correspondence self-study basis, but also their self testing scale, students through self testing, to a certain extent can clearly know their mastery of knowledge, have a definite object in view of the key breakthrough, strengthen study, improve efficiency; the marking operation, also can make the teachers to fully understand the students master knowledge of the situation and my own teaching effect, so as to ensure the teaching quality, produce the positive factors to improve the quality of teaching, so will be the students welcome. Correspondence teaching process should not only pay attention to "teach", but also "letter", and should be based on the "letter"."Letter" is the guidance and answer questions trainees to use written form, also is to use the regular publication of correspondence publications, not regular correspondence counseling information, published textbooks written reminder letters, correspondence, answer form, self-study of students self-study guide and answer questions to strengthen students' enthusiasm, to and the initiative to mobilize the students.

\section{Select the teaching material content, improve the classroom teaching effect.}

Process is a knowledge and information transfer of classroom teaching, and both teachers and students active thinking process, classroom teaching effect, is also one of the main factors that influence the teaching quality of correspondence education [3]. Correspondence textbooks contents, teaching time is short and the concentration. This requires the teachers in teaching according to the prescribed syllabus content, fully familiar with the teaching material content, carefully prepared a set to conform to the characteristic of correspondence education complete lesson plans, in simple and clear language, accurate, scientific, systematic exposition of the curriculum content. In the teaching contents, should develop specifications under the premise of ensuring, pay attention to the selection of materials, to carry out the principle of small but efficient, outstanding key, difficulty. Environmental science students have a considerable part from the environmental monitoring station and the environmental protection agency. Most of them work in the first line, and they are more familiar with the experimental operation. What they need is a theory to guide their practice, therefore, to practice is closely, the basic knowledge, basic theory and basic skills, combined with the actual application of the content should be appropriate to strengthen the key content. Some not commonly used, and the practice is not content, can be used as a general introduction. Such as "Introduction to environmental science"[4], because of the characteristics of the subject, content and system, really boring, difficult to remember. In order to adapt to the characteristics of correspondence teaching, improving the teaching methods of the past, based on familiar with the content of teaching materials and teaching outline, select key, difficulty, doubtful point part and a general understanding of the content in the content of textbooks, teaching and the first to introduce 
students, let students do know the score. Such as the definition, the first chapter is the introduction of the environmental division and the current human and environmental problems facing China, content and sustainable development [5] China environmental protection cause serious environmental situation and environmental problems of China and China is a key content in the teaching, require students to master key. Environmental pollution, cause all kinds of pollution of the similarities, differences, and difficult to grasp, the content is difficult to memory, which belongs to the teaching in the classroom teachers, the difficult part, through repeated control differential explanation, strengthen memory, requiring students to spend a certain amount of time and energy, firmly grasp. The debate, have different ideas about the content, can be to introduce students to some related literatures and reference books and relevant examples, inspire students, leaving the question to students, to discuss, or organized each airs his own views., inspire students interest in learning, for not common or similar to the cause of the pollution situation as a general understanding of the content, require students to master its characteristics. In order to make the students properly combined with cases, in order to strengthen the memory, also can make the teaching get twice the result with half the effort. A non negligible ring teaching is paid attention to the coherence of the teaching contents, make it through, vertical and horizontal comparison, in order to enable students to learn the knowledge deep impression, have a flexible, practical handle very skillfully.

\section{Attach importance to experimental teaching, strengthen students' practical ability.}

The experiment teaching of environmental science specialty occupies a considerable content, and environmental science professional correspondence students mostly came from the environmental monitoring station or the environmental protection agency, most of them work in the first line, the contact more, they are more familiar with the content . At the same time in a certain practical ability, tend to underestimate the experimental teaching in the teaching process, it requires teachers to induce students attach importance to experimental teaching, and through a certain way, strengthen students' practical ability, can proceed from the following aspects:

Choose reasonable experimental project actual situation and experimental properties with the students. Students from different units, all of the different instruments, their work environment also each are not identical, but the content is basically the same, so teachers can choose reasonable experimental project according to the actual situation and the nature of the experiment, the detection experiment can direct students through the operation and use of the experimental instruments. Some of the experimental process is more complex, indicating signal was relatively weak, need quantitative analysis more accurate and experimental projects higher requirements on experimental conditions, can be used more traditional test methods such as CAI system, and has the advantages of simple operation, display clear, records timely, convenient storage, quantitative accurate, and timely to record, analyze and process the information, timely, objective, recording, analysis and processing each index test.

Combining with multimedia projector to improve experimental teaching effect. In the experimental teaching of environmental sciences teaching experiments, such as the joint use of MS302 multimedia signal recording and analysis system with multimedia projector, can make the original experiment indicating information display relatively weak, resolution is not high, small screen, observe the difficulties in change[6].So, to improve the success rate of the experiment, students have difficulties in the whole experiment process do know the score of before the experiment By using the projector to the big screen, index image test to clear amplification, teachers can be combined with the experimental process, to inspire students to analysis operation using laser indicator. To improve the level of experimental technology, it can help students to understand and grasp the experiment method and technology, improve the success rate of and the quality of teaching experiment.

Strengthen experimental operation, optimize the students practical ability. Environmental science students of high performance liquid chromatograph, gas chromatograph, spectrophotometer, mass spectrometry equipment is widely used, but not every student will standardize operations, and 
some even mistake operation. Therefore, requests the teacher and his teaching focus on training students ability, the teacher role transformation from the center of teaching into the eaching organizer, mentor, stratified teaching method on students. Basic experiment, with teacher guidance, emphasizing the use of methods of students skilled instrument, experiment content, grasp the basic skills. Comprehensive experiment, students under the guidance of the teacher, he specifically to finish the experiment content, to solve their own problems. Experimental study on the design, mainly students, the teacher only gives the experimental requirements, students' self selection, independently design and operation, to obtain and analyze the experimental data and conclusions. Some ability, hobbies wide students through innovative experiment, open experiment, arranged into teacher's research group, participated in various design competitions and other methods. This can cultivate students' interest, ability power manually brain can also optimize the students, training mode of talents of formation.

\section{Perfect management system, strict teaching management.}

Environmental Science in Higher Correspondence Education Management is various, need to be strengthened, especially in terms of teaching management, this is one of the important factors affecting the teaching quality improvement and development. Environmental Science Education by correspondence with other adult education, should form a set of not only conforms to the law of education and teaching, teaching organization process and suitable for the characteristics of adult learning. Mainly includes: course design, self-study, tutoring, homework, experiment, practice, examination (examination), graduation thesis and oral defense, each link of a person responsible for, conscientiously implement, to ensure the proper implementation of teaching link. In the management of teaching should also pay attention to often organize teaching quality assessment, establish evaluation index system more scientific, through evaluation, to promote the healthy development of environmental science of correspondence education, improve the social benefits.

In a word, with the development of science, the world is facing the crisis of resources and environment, especially serious China; Outstanding performance in the high energy consumption, heavy environmental pollution. "Eleven five" plan of energy saving and pollution reduction targets, and as a constraint index. Protect environment is everyone's responsibility, the implementation of scientific outlook on development, future scientists, engineers and humane, legal workers is a heavy responsibility in shoulder. Innovation of science and technology and theory needs correct development strategy and ethics as a guide. To reform the teaching of environmental science specialty, improve the environmental science teaching quality, training professional personnel of environmental science fields, each of our teachers can not shirk its responsibility.

\section{References}

[1] Keming Hao,Cultivation of innovative talents and the reform of Higher Education(Peking University Press,Beijing 2004).

[2] Ye Xu,The motivation of the development of adult education of innovation and Implementation Measures,Heilongjiang higher education research,Vol. 83-87 (2002), p.104..

[3] Hui Luo,Application of CAI in the teaching of medical microbiology,Chinese Medical Herald, Vol.3 (2006), p.93.

[4] Yanhua Jing,Lisou Li,Application of CAI in the experimental teaching of Physiology,Modern medicine (SCIENCE EDITION),Vol.4 (2007), p.36.

[5] LonXian Zhong,Role of simulation technology in the teaching reform of human physiological experiments,Journal of Lishui Normal College,Vol.26(2004), p.35.

[6] La Saike,etc,Looking from the present educational content to global development (Education Science Publications, Beijing 1996). 